\title{
Surface energy and wettability of polymers light- cured by two different systems
}

\author{
Fatima Maria NAMEN ${ }^{1}$, Eduardo FERRANDINI'2, João GALAN JUNIOR ${ }^{3}$
}

1- DDS, MSD, PhD, Department of Biomaterials, Fluminense Federal University, Niterói, RJ, Brazil.
2- DDS, MSD, Dental clinician, Fluminense Federal University, Niterói, RJ, Brazil.
3- DDS, MSD, PhD, Department of Dental Materials, State University of Rio de Janeiro, Rio de Janeiro, RJ, Brazil.

Corresponding address: João Galan Jr. - Av. Visconde Rio Branco 767 /1401 - 24020-006 - Niterói, RJ - Brazil - Phone: 55-21-26221663 - Fax: 55-2126221663 - e-mail: galanjr.joao@gmail.com

Received: October 06, 2009 - Modification: May 02, 2010 - Accepted: May 25, 2010

\section{ABSTRACT}

\begin{abstract}
bjectives: This study evaluated the surface energy and wettability of composite resins polymerized by different light-curing units to ascertain the good wetting of tooth surfaces to achieve adhesion. Material and Method: Filtek Z350 (3M ESPE), Admira (VOCO) and Grandio (VOCO) resins were selected for the testing procedures. The resins were light cured using LED and Halogen devices. Contact angles were measured goniometrically (Ramé-Hart F100) using water and glycerol as test liquids. Surface energy values were calculated with a software program (DROPimage Standard) that uses the harmonic mean method applied to the acid-base theory. The data were analyzed statistically by ANOVA and Tukey's test with a significance of 0.05 . Results and Conclusions: No statistically significant differences were found between the values of surface energy. The measured wettability differed statistically in most combinations as a function of the type of composite resin, type of light-curing unit, and the test liquid.
\end{abstract}

Key words: Wettability. Surface energy. Composite resins. Dental light curing.

\section{INTRODUCTION}

Light-cured composite resins (LCCRs) have been studied extensively in recent years. The formulation proposed by Bowen ${ }^{1}$ (1963), which is still in use today albeit with slight modifications, consists basically of a resin matrix, filler particles, monomers and a photo absorbing compound ${ }^{18}$.

The latest development in this field has been the introduction of low shrinkage monomers and nanofiller particles ${ }^{17}$. LCCR (polymerase chain reaction) materials are present in Filtec Z350 (3M/ESPE, Saint Paul, MN, USA), which combines nanometric particles and nanoclusters in a conventional resin matrix, and in Admira (VOCO, Cuxhaven, Germany), whose resin matrix contains ormocer, an organically modified ceramic ${ }^{22}$.

The light-curing units (LCUs) equipped with a light-emitting diode (LED), which produces cold light at $450 \mathrm{~nm}$ wavelength, is a promising device of costs and efficiency. However, the LCU operating with a halogen lamp is still the first choice of clinicians and extensive research has been dedicated to testing its efficiency ${ }^{13,23}$.

The present research focused on one of the important properties of LCCRs - surface free energy (SFE), to study the interaction between the forces of cohesion and the forces of adhesion that determine the occurrence of surface wetting.

The wetting performance of etched enamel is important in all types of adhesive restorations because of the close interaction between the surface free energy of the etched enamel and the wettability of the luting and bonding material. The enamel-composite bond strength depends on these interactions $\mathrm{s}^{2,12}$. The contact angle measurement method is probably the most definite way to determine cell surface hydrophobic. The angle is very high for water if substrata are hydrophobic. If the surface is hydrophilic, the droplet quickly dissipates and the measured angle is low. Contact angles values vary with surface topography, surface tension of the liquid, surface energy of the substrate and the level of interaction between the liquid and solid ${ }^{19}$. Hydrophobic materials are more color-stable and stain-resistant than hydrophilic materials ${ }^{11}$. 
Gaps formed at the tooth/restoration interface may be caused by inadequate wetting of the tooth surface by the restorative material along the preparation walls during placement ${ }^{9}$. Surfaces with a low surface free energy minimize plaque formation ${ }^{16}$.

To calculate de SFE, the first step consists of measuring the contact angle (CA) between the solid under study and the test liquid, using a contact angle goniometer. The CA which is the macroscopic expression of the micro and macroscopic phenomena occurring between the solid, the test liquid ${ }^{4,6}$.

The SFE can be calculated based on two theories. The acid-base theory involves the multicomponent approach, whereby the SFE occurs through dispersive interactions or Lifshitzvan der Waals (LW) and Lewis acid-base (AB) interactions. The second approach involves the equation-of-state theory, which is highly criticized from the thermodynamic standpoint. Although these theories are based on different concepts, they share the same basic idea, i.e., they attempt to express the reverse work of adhesion of some of the components of the interfacial tension between liquids and solids ${ }^{5}$.

The aim of this work was to evaluate the variations in the surface energy of various composite resins after curing by LED and halogen curing devices, based on contact angles and surface free energy.

\section{MATERIAL AND METHODS}

\section{Test preparation}

Thirty-six test specimens of composite resins (Admira-Voco, Cuxhaven, Germany; Filtec Z3503M/ESPE, Saint Paul, MN, USA; Grandio-Voco, Cuxhaven, Germany) were prepared in a $10 \mathrm{~mm}$ diameter, 2-mm thick articulated brass matrix. The specimens were finished with Sof-Lex discs (3M/ ESPE) and polished with Kota diamond paste (Kota Dental Products, São Paulo, Brazil).

The LCUs employed were a LED device (Elipar Freelight II $-1000 \mathrm{~mW} / \mathrm{cm}^{2}, 3 \mathrm{M} / \mathrm{ESPE}$ ) and a halogen device (VIP TM $500 \mathrm{~mW} / \mathrm{cm}^{2}$ and 600 $\mathrm{mW} / \mathrm{cm}^{2}$, Bisco, Inc., Schaumburg, IL, USA). The light emission control was preset with a radiometer (Demetron 100P/N; Demetron Research Corp.,
Danbury, CT, USA).

The materials (shade A2) were inserted into the matrix in two portions and pressed with two microscope slides to achieve a smooth flat surface, after which they were light-cured in the specimens center for $20 \mathrm{~s}$ on each side. Twelve samples of each composite were prepared, 6 were light-cured wit a LED LCU and 6 with a halogen lamp. All specimens were stored in dark vials at $8^{\circ} \mathrm{C}$ for 1 week, after which they were finished and polished before testing.

\section{Contact angle measurements}

The static contact angles were measured with a goniometer (Ramé-Hart 100-FO, Netcong, NJ, USA) using deionized water and glycerol as test liquids (Table 1). The volume of each drop was standardized at $2 \mu \mathrm{L}$. The 36 samples were divided into 12 groups of 6 test specimens each, and 6 drops of each liquid were used for the measurements. The computer was set to record 10 contact angle measurements of each drop, so 360 measurements were made for each group, making a total of 4,320 measurements.

\section{Determination of surface free energy (SFE)}

The SFE was determined based on the harmonic mean method described by $\mathrm{Wu}^{22}$ (1995). Because two test liquids are required to calculate the SFE by this method, the samples were divided into 6 groups of 6 test specimens each. A different LCU and test liquid were used for each group. The contact angle values determined for each group were stored in the computer, and the surface energy was calculated using DROPimage Standard software, Netcong, NJ, USA. The values were done by the soft but the calculations can be done by Youngs Equation: $\mathrm{Y} 2=\mathrm{y} 12+\mathrm{y} 1 \cos \theta$ and with the acid-base theory.

\section{Statistical analysis}

Statistical inter- and intra-group analyses of the data were made using ANOVA and Tukey's test at 0.05 significance level.

\section{RESULTS}

Table 2 shows the mean values and standard deviations of the interactions among the various types of LCCRs, LCUs, and test liquids, as well as the statistically significant differences among the

Table 1- Test liquids

\begin{tabular}{cccccccccc}
\hline Liquid & Source & Purity & $\rho$ & $\gamma$ & $\gamma^{\mathrm{Lw}}$ & $\gamma^{+}$ & $\gamma$ & \multicolumn{2}{c}{ Chemical Formulation } \\
\hline Water & PUC & $99 \%$ & 0.998 & 71.8 & 21.8 & 25.5 & 25.5 & $\mathrm{H}_{2} \mathrm{O}$ \\
Glycerol & VETEC/PUC & $99.5 \%$ & 1.261 & 64 & 34 & 3.92 & 57.4 & $\mathrm{C}_{3} \mathrm{H}_{5}(\mathrm{OH})_{3}$ \\
\hline
\end{tabular}

$\rho=$ Relative equilibrium pressure,$\gamma=$ Interface tension , $\gamma^{\mathrm{LW}}=$ Interation forces (London dispersive - Debye dipole and Keeson dipole-dipole) $\gamma^{+}=$Acidic part -acceptor, $\gamma=$ Basic part - donor 
Table 2- Mean values of Contact Angles (Mean \pm SD)

\begin{tabular}{ccccc}
\hline Material & Halogen/Water & Halogen/Glycerol & LED/Water & LED/Glycerol \\
\hline Admira & $71.44 \pm 3.653^{\mathrm{a}}$ & $74.45 \pm 3.924^{\mathrm{a}}$ & $66.96 \pm 3.07^{\mathrm{a}}$ & $71.33 \pm 3.244^{\mathrm{a}}$ \\
Filtek Z350 & $67.22 \pm 4.334^{\mathrm{a}}$ & $65.57 \pm 2.802^{\mathrm{a}}$ & $67.62 \pm 4.744^{\mathrm{a}}$ & $67.33 \pm 4.246^{\mathrm{a}}$ \\
Grandio & $73.64 \pm 1.636^{\mathrm{a}}$ & $74.35 \pm 1.521^{\mathrm{a}}$ & $72.97 \pm 2.034^{\mathrm{a}}$ & $59.19 \pm 3.780^{\mathrm{b}}$ \\
\hline
\end{tabular}

Tukey's multiple comparisons- (Same letters=not statistically significant $p>0.05$ )

$\mathrm{SD}=$ standard deviation

Table 3- Mean, Standard Deviation and Standard Error for surface free energy $\left(\mathrm{mJ} / \mathrm{m}^{2}\right)$

\begin{tabular}{ccc}
\hline Material & Halogen Lamp & LED \\
\hline Admira & $36.13 \pm 2.293(0.9359)$ & $40.17 \pm 4.804(1.961)$ \\
Grandio & $34.74 \pm 1.960(0.8002)$ & $39.59 \pm 5.808(2.598)$ \\
\hline Filtek Z350 & $38.56 \pm 2.119(0.8651)$ & $38.45 \pm 2.735(1.117)$ \\
\hline
\end{tabular}

$p>0.05-$ Not statistically significant

groups as indicated by the Tukey's test.

The resin Admira $\left(74.45^{\circ}\right)$, using glycerol as the test liquid and the halogen lamp as the LCU, yielded the highest mean CA value, while Grandio (59.19) resin tested with glycerol, using LED as the light source, yielded the lowest CA value.

The inter- and intra-group CA values showed no significant difference ( $p>0.05)$ for the Filtec $Z 350$ resin, but all values obtained for the resin Grandio showed significant differences $(p<0.05)$.

The SFE results listed in Table 3 were subjected to Tukey's test, which indicated the absence of statistically significant differences among the groups.

\section{DISCUSSION}

In the present study, the CA varied among some groups. The main controllable variables involved in CA measurements are the light-curing process, the test liquids and the chemical composition of the resin under study.

All samples (shade A2) were subjected to $40 \mathrm{~s}$ of light incidence upon the center of the sample, which according to Lindberg, Peutzfeldt and Van Dijken ${ }^{13}$ (2004) is sufficient to cure the entire surface of such samples.

Although the intensity of the VIP TM (Bisco) halogen lamp varied from 500 to $600 \mathrm{~mW} / \mathrm{cm}^{2}$, we do not believe this variation impaired the polymerization of the test specimens of the 3 resins. The intensity of light emitted by a halogen lamp is lower than that emitted by a LED unit ${ }^{14}$, but its values still exceed 280 to $300 \mathrm{~mW} / \mathrm{cm}^{2}$, according to Caughman, Rueggeberg and Curtis ${ }^{3}$ (1995). In view of the lack of information about the surface energy of these materials, it is difficult to compare our results to those of other author ${ }^{8}$.
The test liquids used here had different polarities, in spite of similar values ${ }^{10}$ which explains the mean CA values ranging from $59.19^{\circ}$ to $74.45^{\circ}$ obtained in this study. The degree of purity and the numerous measurements yielded reliable results and low standard deviations. Although Zisman ${ }^{24}$ (1964) stated that the volume of the drop does not influence CA values, this volume, as well as room temperature and humidity, were standardized in this study in order to reduce the number of variables.

The organic matrix of Admira resin is composed of ormocer, siloxane organic/inorganic polymer, Bis-GMa, HEMA, UDMA, $\mathrm{Fe}_{2} \mathrm{O}_{3}$, TiO and 4-tertbutylcatechol (TBC), and its inorganic matrix contains Ba-Al borosilicate, a silicon dioxide (0.04$0.7 \mu \mathrm{m})-78 \%$ in weight and $56 \%$ in volume. The presence of these high surface energy particles, which in some samples may have been located close to the surface, could cause a decrease in measured $\mathrm{CA}$ values. Light curing of the organic material, which closes the carbon chains, also probably interferes in the expression of these particles even in the deepest layers.

The diameters of the inorganic particles of Filtec Z350 and Grandio resins are nanometric. Wu ${ }^{22}$ (1973) argues that the homogeneous dispersion of inorganic particles in the polymeric matrix is critical, a statement confirmed by Von Werne and Patten ${ }^{20}$ (2001). Hydrophobic polymers and inorganic hydrophilic particles are physically difficult to mix, and phase separation or agglomeration is common in such mixtures, resulting, according to the aforementioned author, in alterations in their mechanical, optical and electrical properties. These particles can be treated chemically used to produce a more hydrophobic or hydrophilic surface.

As shown in Table 2, the CA values of the Filtek Z350 resin showed no major variations in any of 
the combinations. In view of these results, it is reasonable to assume that the components of the resin in these test specimens were distributed more homogeneously. The CA values of the Admira resin revealed greater variations in the two test liquids and the two LCUs. Among the 3 resins of this study, this one showed the highest CA variability.

Table 3 lists the mean values of the total SFE calculated for each LCCR with respective SD, indicating no significant differences among the groups. The Admira resin showed the highest SFE value when light-cured with the LED unit $(40.17 \mathrm{~mJ} /$ $\mathrm{m}^{2}$ ), while the Grandio resin displayed the lowest SFE when photo-activated by the conventional halogen lamp $\left(34.74 \mathrm{~mJ} / \mathrm{m}^{2}\right)$.

The statistical analysis of the resins' SFE data confirmed that the different types of LCU employed to polymerize the resins did not influence these results. This finding is congruent with that reported by Glantz and Larsson' (1971), although the resins tested by these authors belong to another generation of composites, whose chemical compositions differ considerably from those used in our study.

Milosevic $^{15}$ (1992) who studied the adhesion of saliva films on composite resins, stated that polymers are usually known as low-SFE materials with values of about $40 \mathrm{~mJ} / \mathrm{m}^{2}$, and that the particles of their inorganic load have high SFE values. All the results obtained in the present research (Table 3) are in agreement with those of this author.

\section{CONCLUSIONS}

It may be concluded that: 1 . The contact angles of the 3 polymers studied here did not differ significantly, as did their wettability. The research recommends the material that showed the highest contact angle; 2. Polymerization with LED or halogen units did not alter the surface free energy of the composite resins.

\section{REFERENCES}

1- Bowen RL. Properties of a silica-reinforced polymer for dental restorations. J Am Dent Assoc. 1963;66:57-64.

2- Burke FJ, Combe EC, Douglas WH. Dentine bonding systems:

1. Mode of action. Dent Update. 2000;27;85-8,90,92-3.

3- Caughman WF, Rueggeberg FA, Curtis JW Jr. Clinical guidelines for photocuring restorative resins. J Am Dent Assoc. $1995 ; 126: 1280-2,1284,1286$.

4- Combe EC, Owen BA, Hodges JS. A protocol for determining the surface free energy of dental materials. Dent Mater. 2004;20:2628.
5- Della Volpe C, Siboni S. Troubleshooting of surface free energy acid-base theory applied to surfaces: the case of Good, Van Oss and Chaudhury theory. In: Mittal KL, Anderson HR, editors. Acidbase interactions: relevance to adhesion science and technology. Utrecht: VSP; 2000. p. 55-90.

6- Gajewski A. A method for contact angle measurements under flow conditions. Int J Heat Mass Transfer. 2005;48:4829-34.

7- Glantz PO, Larsson LA. The wettability of composite resinous filling materials. Acta Odontol Scand. 1971;29:539-48.

8- Hahnel S, Rosentritt M, Bürgers R, Handel G. Surface properties and in vitro Streptococcus mutans adhesion to dental resin polymers. J Mater Sci Mater Med. 2008;19:2619-27.

9- Hakimeh S, Vaidyanathan J, Houpt ML, Vaidyanathan TK, Von Hagen S. Microleakage of compomer class $V$ restorations: effect of load cycling, thermal cycling, and cavity shape differences. J Prosthet Dent. 2000;83:194-203.

10- Holländer A. On the selection of test liquids for the evaluation of acid-base properties os solid surfaces by contact angle goniometry. J Colloid Interf Sci. 1995;169:493-6.

11- Iazzetti G, Burgess JO, Gardiner D, Ripps A. Color stability of fluoride-containing restorative materials. Oper Dent. 2000;25:520-5.

12- Jardel V, Degrange M, Picard B, Derrien G. Surface energy of etched ceramic. Int J Prosthodont. 1999;12:415-8.

13- Lindberg A, Peutzfeldt A, van Dijken JW. Curing depths of a universal hybrid and a flowable resin composite cured with quartz tungsten halogen and light-emitting diode units. Acta Odontol Scand. 2004;62:97-101.

14- Mills RW, Jandt KD, Ashworth SH. Dental composite depth of cure with halogen and blue light emitting diode technology. $\mathrm{Br}$ Dent J. 1999;186:388-91.

15- Milosevic A. The influence of surface finish and in-vitro pellicle on contact-angle measurement and surface morphology of three comercially available composite restoratives. J Oral Rehabil. 1992; 19:85-97.

16- Quirynen M, Bollen CM. The influence of surface roughness and surface-free energy on supra- and subgingival plaque formation in man. A review of the literature. J Clin Periodontol. 1995;22:1-14. 17- Schimidt D, Shah D, Giannelis E. New advances in polymer/ layered silicate nanocomposites. Curr Opin Solid State Mater Sci. 2002;26:205-12.

18- Silikas N, Kavvadia K, Eliades G, Watts D. Surface characterization of modern resin composites: a multitechnique approach. Am J Dent. 2005;18:95-100.

19- Van Oss CJ, Good RJ, Chaundhury MK. Additive and nonadditive surface tension components and the interpretation of contact angles. Langmuir. 1988;4:884-91.

20- Von Werne T, Patten TE. Atom transfer radical polymerization from nanoparticles: a tool for the preparation of well-defined hybrid nanostructures and for understanding the chemistry of controlled/"living" radical polymerizations from surfaces. J Am Chem Soc. 2001;123:7497-505.

21- Wolter H. Bulk-ORMOCER and ORMOCER composites. In: Annual Report. Fraunhofer Institut fuer Silikatforschung; 1995. p.45-51.

22- Wu S. Polar and nonpolar interactions in adhesion. J Adhes. 1973;5:39-55.

23- Yoon TH, Lee YK, Lim BS, Kim CW. Degree of polymerization of resin composites by different light sources. J Oral Rehabil. 2002;29:1165-73.

24- Zisman W. Relation of the equilibrium contact angle to liquid and solid constitution. Adv Chem Ser. 1964;43:1-51. 